\title{
Reversible Oxygenation of 2,4-Diaminobutanoic Acid-Co(II) Complexes
}

\author{
Xiang Cheng, Yan Huang, Hui Li, Fan Yue, Hongmei Wen, and Jide Wang \\ Key Laboratory of Oil and Gas Fine Chemicals, Ministry of Education and Xinjiang Uyghur Autonomous Region, \\ College of Chemistry and Chemical Engineering, Xinjiang University, Urumqi 830046, China
}

Correspondence should be addressed to Jide Wang; awangjd@sina.cn

Received 20 May 2016; Accepted 26 July 2016

Academic Editor: Guillermo Mendoza-Diaz

Copyright (C) 2016 Xiang Cheng et al. This is an open access article distributed under the Creative Commons Attribution License, which permits unrestricted use, distribution, and reproduction in any medium, provided the original work is properly cited.

This paper introduces the structural characterization and studies on reversible oxygenation behavior of a new oxygen carrier Co(II)2,4-diaminobutanoic acid (DABA) complex in aqueous solution. The composition of the oxygenated complex was determined by gas volumetric method, molar ratio method, and mass spectrometry, and the formula of the oxygenated complex was determined to be $\left[\mathrm{Co}(\mathrm{DABA})_{2} \mathrm{O}_{2}\right]$. In aqueous solution, the complex can continuously uptake and release dioxygen and exhibit excellent reversibility of oxygenation and deoxygenation ability. This complex can maintain $50 \%$ of its original oxygenation capacity after 30 cycles in $24 \mathrm{~h}$ and retain $5 \%$ of the original oxygenation capacity after more than 260 cycles after $72 \mathrm{~h}$. When a ligand analogue was linked to histidine (His), the new complex exhibited as excellent reversible oxygenation property as His-Co(II) complex. Insight into the relationship between structural detail and oxygenation properties will provide valuable suggestion for a new family of oxygen carriers.

\section{Introduction}

Oxygen carriers are a series of natural/synthesized products that can reversibly bind dioxygen [1]. Studies on oxygen carriers present important implications in revealing the mechanism of dioxygen transfer and storage in vivo, for example, in hemoglobin and myohemoglobin [2-5]. Amino acids can form various metal complexes with $\mathrm{Fe}(\mathrm{II}), \mathrm{Cu}(\mathrm{I})$, $\mathrm{Co}(\mathrm{II})$, and other metal ions $[1,6]$. These types of metal complexes are active centers of biological macromolecules, such as peptidyl glycine $\alpha$-hydroxylating monooxygenase, dopamine $\beta$-monooxygenase, myoglobin, and hemoglobin [7-9]. Researches on metal complexes of amino acids can be an aid to prove the biological activities and function mechanisms of these complexes in organisms. The design and synthesis of transition metal complexes with good affinity to dioxygen and long reversible oxygenation life are key to develop natural oxygen carriers. The most commonly used central metal ions are $\mathrm{Fe}(\mathrm{II}), \mathrm{Cu}(\mathrm{I}), \mathrm{Co}(\mathrm{II})$, and $\mathrm{Mn}$ (II) [10-16], and typical ligands include polyamine, Schiff base, amino acids, and porphyrins [14, 15, 17-19]. Certain compounds show good reversible oxygen absorbing performance in solid state $[20,21]$, at low temperature, or in nonaqueous media $[22,23]$. However, most known model compounds exhibit poorly reversible oxygenation behavior in aqueous solution. Only histidine-Co(II) and iodo-histidineCo(II) [24-26] complexes exhibit excellent reversibility of dioxygen uptake in aqueous solution to date. The lack of accumulation on the relationship between structural details and oxygenation properties leads to a knowledge gap in the development of novel, inexpensive oxygen carriers. We previously supposed that the special structure of histidine$\mathrm{Co}(\mathrm{II})$ is the key to the reversibility of dioxygen uptake [14, $24]$. To prove this concept, we designed and selected several histidine ligand analogues, such as $\beta$-(2-Pyridyl)- $\alpha$-alanine [24] and 2, 3-diaminopropionic acid [27], and investigated the oxygenation of the resulting $\mathrm{Co}$ (II) complexes. Both complexes showed excellent reversible oxygenation as histidine$\mathrm{Co}(\mathrm{II})$ and supported our assumption. We then selected UVVis spectrophotometry to detect the oxygenation properties of potential oxygen carriers. The technique was selected because of its simplicity and usefulness in investigating oxygenation in a solution, as UV-Vis absorption spectrum of the oxygenated cobalt complex is significantly distinct from 
its deoxygenated species. Therefore, the oxygenation and reversibility of the complexes can be observed precisely by using UV-Vis spectrophotometry through monitoring color variations.

In this paper, the reversible oxygenation of 2,4diaminobutanoic acid-Co(II) was investigated by UV-Vis spectra and oxygenmetry in aqueous solution at room temperature. The formation of the oxygenated complex was characterized by UV-Vis spectrophotometry, infrared (IR) spectroscopy, and mass spectrometry (MS), and the composition of the oxygenated complex was determined by molar ratio method and gas volumetric method. The reversible cycles of oxygenation and the oxygenation life of the complex were tested in aqueous solution, and all results demonstrated that the complex exhibited excellent reversibility in its oxygenation. This work represents a shift away from histidine and histidine analogues, which have previously been confirmed to undergo reversible oxygenation/deoxygenation events, and provides a link to biological systems that utilize iron and copper for this purpose in vivo.

\section{Experimental}

2.1. Materials. L-2,4-Diaminobutanoic acid hydrochloride $(\mathrm{DABA} \cdot 2 \mathrm{HCl})$ and $\mathrm{Co}(\mathrm{OAc})_{2} \cdot 4 \mathrm{H}_{2} \mathrm{O}$ were obtained from Shanghai Hanhong Chemical Co. and Shanghai Chemical Regents Co., respectively. The reagents were used without further purification. $\mathrm{A} \mathrm{CO}_{2}$-free $\mathrm{NaOH}$ solution $\left(0.1 \mathrm{~mol} \cdot \mathrm{dm}^{-3}\right)$ was prepared by standardization with potassium acid phthalate. An $\mathrm{HCl}$ solution $\left(0.1 \mathrm{~mol} \cdot \mathrm{dm}^{-3}\right)$ was prepared from concentrated hydrochloric acid and standardized with anhydrous sodium carbonate. High-purity (99.99\%) $\mathrm{O}_{2}$ and $\mathrm{N}_{2}$ were used.

2.2. UV-Vis Spectrophotometry. Sample solutions were determined by UV-Vis spectrophotometry. $\mathrm{N}_{2}$ and $\mathrm{O}_{2}$ were alternately bubbled into the solution during testing. Optical absorption spectra were recorded at $25^{\circ} \mathrm{C} \pm 0.1^{\circ} \mathrm{C}$ on a Shimadzu UV2450 spectrophotometer using a $1 \mathrm{~cm}$ cuvette over the spectral range of $250-600 \mathrm{~nm}$.

2.3. IR Spectroscopy. The ligand and complex aqueous solutions $\left(C=1.0 \mathrm{~mol} \cdot \mathrm{dm}^{-3}\right)$ were analyzed by Bruker EQUINOX 55 liquid IR spectroscopy after air exposure for $1 \mathrm{~h}$. The $\mathrm{pH}$ value of the complex solution was adjusted to 10 by adding dilute $\mathrm{NaOH}$ solution $\left(0.1 \mathrm{~mol} \cdot \mathrm{dm}^{-3}\right)$.

2.4. Mass Spectrometry Method. MS was performed on a Waters Quattro Premier XE mass spectrometer equipped with an electrospray ionization source (Micromass, Manchester, UK). The mass analyzer was operated in positive ionization mode for all analytes, and the optimized parameters were as follows: source temperature, $120^{\circ} \mathrm{C}$; desolvation temperature, $450^{\circ} \mathrm{C}$; capillary voltage, $3.5 \mathrm{kV}$; desolvation gas flow, $400 \mathrm{~L} \cdot \mathrm{h}^{-1}$; cone voltage, $60 \mathrm{~V}$; cone gas flow, $50 \mathrm{~L} \cdot \mathrm{h}^{-1}$; collision energy, $20 \mathrm{eV}$; and multiplier, $650 \mathrm{~V}$. The mass spectra collected in full-scan positive ion mode were obtained by scanning over the mass range of $\mathrm{m} / z 50$ to $\mathrm{m} / z 900$. Nitrogen (99.999\% purity) was used as desolvation and nebulization gas, and ultrapure argon (99.999\% purity) was used as collision gas. A full-scan mass spectrum was obtained by flow injection analysis of individual $1.0 \times 10^{-2} \mathrm{~mol} \cdot \mathrm{dm}^{-3}$ solutions in water. Acetonitrile/water $(50: 50, \mathrm{v} / \mathrm{v})$ was used as the mobile phase. The concentration of DABA and the complex employed for MS determination was $2.0 \times 10^{-2} \mathrm{~mol} \cdot \mathrm{dm}^{-3}$.

2.5. Molar Ratio Method. Eight aliquots of DABA solution $\left(C_{\mathrm{DABA}}=4.0 \times 10^{-4} \mathrm{~mol} \cdot \mathrm{dm}^{-3}\right)$ were separately added to $10.0 \mathrm{~mL}$ volumetric flasks at $0.5,1.0,1.5,2.0,2.5,3.0,3.5$, and $4.0 \mathrm{~mL}$. About $1.0 \mathrm{~mL}$ of $2.0 \times 10^{-4} \mathrm{~mol} \cdot \mathrm{dm}^{-3} \mathrm{Co}$ (II) solution was then added to each flask, and a $\mathrm{pH} 10$ borate buffer solution was added to volume. $\mathrm{O}_{2}$ was bubbled into the sample solutions for $10 \mathrm{~min}$. The absorbance of the solutions was determined using a UV2450 spectrophotometer with a $1 \mathrm{~cm}$ cuvette at $314 \mathrm{~nm}$.

2.6. Gas Volumetric Method. A $10.0 \mathrm{~mL}$ of $\mathrm{Co}(\mathrm{II})(1.0 \times$ $\left.10^{-1} \mathrm{~mol} \cdot \mathrm{dm}^{-3}\right)$ and $10.0 \mathrm{~mL}$ of DABA $\left(2.0 \times 10^{-1} \mathrm{~mol} \cdot \mathrm{dm}^{-3}\right)$ were mixed together in a conical flask in a glove box. The aqueous solution was immediately placed on a eudiometer, which had been filled with oxygen in advance. The decreasing volume of oxygen with time was measured until volume remained constant. The final volume of oxygen was then recorded.

2.7. Oxygenmetry. The concentration of dissolved $\mathrm{O}_{2}$ in solution would be consumed during oxygenation, which displays the oxygenation evolution of the complex. Hence, the concentrations of dissolved $\mathrm{O}_{2}$ in solution were measured using a dissolved oxygen meter over a $\mathrm{pH}$ range of 2 to 10 at $25^{\circ} \mathrm{C} \pm 0.1^{\circ} \mathrm{C}$. $\mathrm{KCl}\left(0.1 \mathrm{~mol} \cdot \mathrm{dm}^{-3}\right)$ was used to maintain the solution at a constant ionic strength. A $25.0 \mathrm{~mL}$ of $1.2 \times 10^{-3} \mathrm{~mol} \cdot \mathrm{dm}^{-3}$ ligand solution was transferred to a titration pool and maintained at $\mathrm{pH}<2$ by adding $2.0 \mathrm{~mL}$ of $0.10 \mathrm{~mol} \cdot \mathrm{dm}^{-3} \mathrm{HCl}$ solution to prevent oxygenation prior to testing. Afterward, $25.0 \mathrm{~mL}$ of $6.0 \times 10^{-4} \mathrm{~mol} \cdot \mathrm{dm}^{-3} \mathrm{Co}$ (II) solution was added to the pool, and the solution was sealed with $20.0 \mathrm{~mL}$ of cyclohexane to prevent air penetration. Therefore, the concentration changes of the dissolved $\mathrm{O}_{2}$ in solution are reasonably related to the oxygenation of the $\mathrm{Co}(\mathrm{DABA})_{2}$ complex. The diluted $\mathrm{NaOH}$ solution was used to adjust the $\mathrm{pH}$ values of the solution from 2 to 10 , and the $\mathrm{O}_{2}$ concentrations in solution were detected at each $\mathrm{pH}$. After the $\mathrm{pH}$ reached 10 , dilute $\mathrm{HCl}$ was added to adjust solution $\mathrm{pH}$ values from 10 to 2 and to observe the reversibility of releasing dioxygen from the complex.

2.8. Construction of the Absorption (A)-pH Curve. $25.0 \mathrm{~mL}$ of $4.0 \times 10^{-4} \mathrm{~mol} \cdot \mathrm{dm}^{-3}$ solution was initially adjusted to $\mathrm{pH} 2$ with dilute $\mathrm{HCl}$ solution and $25.0 \mathrm{~mL}$ of $2.0 \times 10^{-4} \mathrm{~mol} \cdot \mathrm{dm}^{-3}$ $\mathrm{Co}(\mathrm{II})$ solution was added and mixed. The absorption $(A)$ of amino acid-cobalt solution was determined by UV-Vis spectrophotometry at the maximum absorption peak $\left(\lambda_{\max }\right)$ 


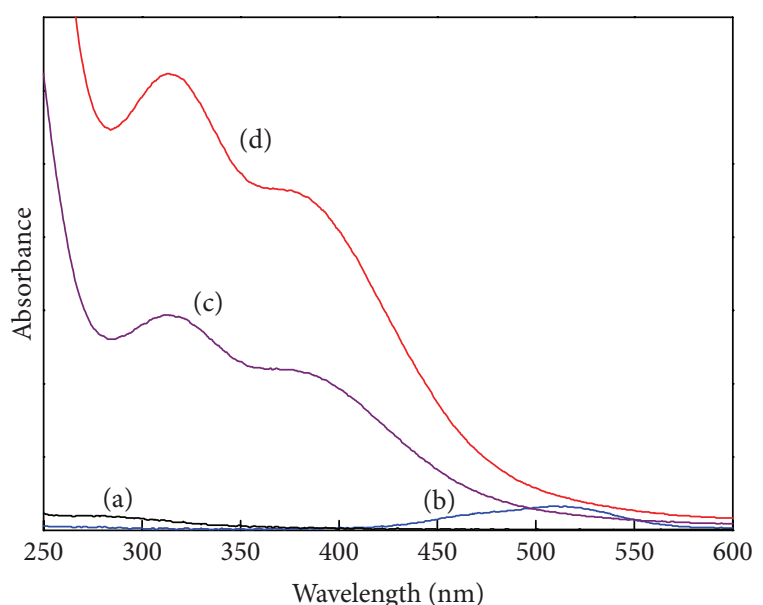

FIgURE 1: Optical absorption spectra of DABA, Co(II), and complexes in aqueous solution at room temperature (absorption spectra of DABA (a), Co(II) (b), DABA-Co(II) in $\mathrm{N}_{2}$ (c), and DABA$\mathrm{Co}(\mathrm{II})$ in $\mathrm{O}_{2}$ (d). $C_{\mathrm{DABA}}=4.0 \times 10^{-4} \mathrm{~mol} \cdot \mathrm{dm}^{-3}$ and $C_{\mathrm{Co}(\mathrm{II})}=2.0 \times$ $\left.10^{-4} \mathrm{~mol} \cdot \mathrm{dm}^{-3}\right)$.

of $314 \mathrm{~nm}$. Solution $\mathrm{pH}$ was then adjusted from 2 to 12 with dilute $\mathrm{NaOH}$. Absorption $A$ was recorded with the variation of $\mathrm{pH}$, and the suitable $\mathrm{pH}$ was selected from the $A$ - $\mathrm{pH}$ curve.

2.9. Determination of Reversible Ability for Taking and Releasing Dioxygen. The reversibility of oxygenation and the kinetics of oxygenation and deoxygenation were carried out with a PP2 flowing injection apparatus [24]. Oxygenation and deoxygenation reversibility of the $\mathrm{Co}(\mathrm{DABA})_{2}$ complex was determined by recording absorbance changes at $314 \mathrm{~nm}$ upon saturating the solution with $\mathrm{O}_{2}$ and $\mathrm{N}_{2}$. Absorbance difference, $\Delta A$, was used to evaluate $\mathrm{O}_{2}$ uptake ability. The number of oxygenation-deoxygenation cycles was used to estimate the endurance to autoxidation of the complex.

2.10. Calculation. All calculations were performed with the Gaussian 03W program package [28]. Full geometry optimization computations were performed using the B3LYP method. In all calculations, a LANL2DZ basis set along with the corresponding effective core potential was used for Co metal atoms. The 6-31G basis set was used for $\mathrm{C}, \mathrm{H}, \mathrm{N}$, and $\mathrm{O}$ atoms. The structural models of the studied compounds are shown in Figure 10, and the multiplicity of the complexes was regarded as a quartet for $\operatorname{Co}(\mathrm{DABA})_{2}$, a doublet for $\mathrm{Co}(\mathrm{DABA})_{2} \mathrm{O}_{2}$, and a singlet for $(\mathrm{DABA})_{2}, \mathrm{Co}\left(\mathrm{O}_{2}\right)$, and $\mathrm{Co}(\mathrm{DABA})_{2}$.

\section{Results and Discussion}

\subsection{Formation of the Complex}

3.1.1. UV-Vis Spectrophotometry. The optical absorption spectra of the ligand $\left(4.0 \times 10^{-4} \mathrm{~mol} \cdot \mathrm{dm}^{-3}\right)$ and $\mathrm{Co}$ (II) $(2.0$ $\times 10^{-4} \mathrm{~mol} \cdot \mathrm{dm}^{-3}$ ) were separately determined. The ligand showed no evident absorption within the range of $200 \mathrm{~nm}$ to $600 \mathrm{~nm}$ (Figure 1, curve (a)), and Co(II) solutions showed a

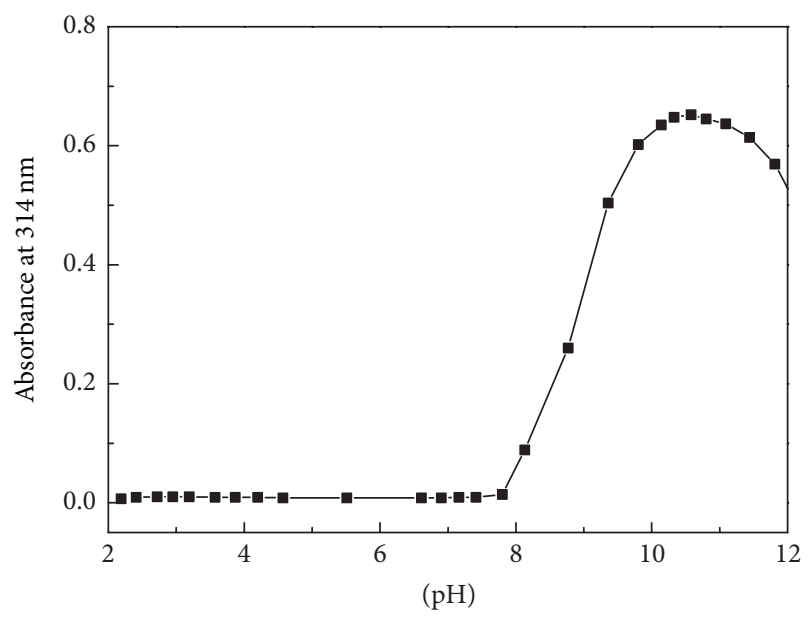

Figure 2: $A$-pH curve of the oxygenated DABA-Co(II) complex $\left(C_{\text {DABA }}=4.0 \times 10^{-4} \mathrm{~mol} \cdot \mathrm{dm}^{-3}, C_{\mathrm{Co}(\mathrm{II})}=2.0 \times 10^{-4} \mathrm{~mol} \cdot \mathrm{dm}^{-3}\right)$.

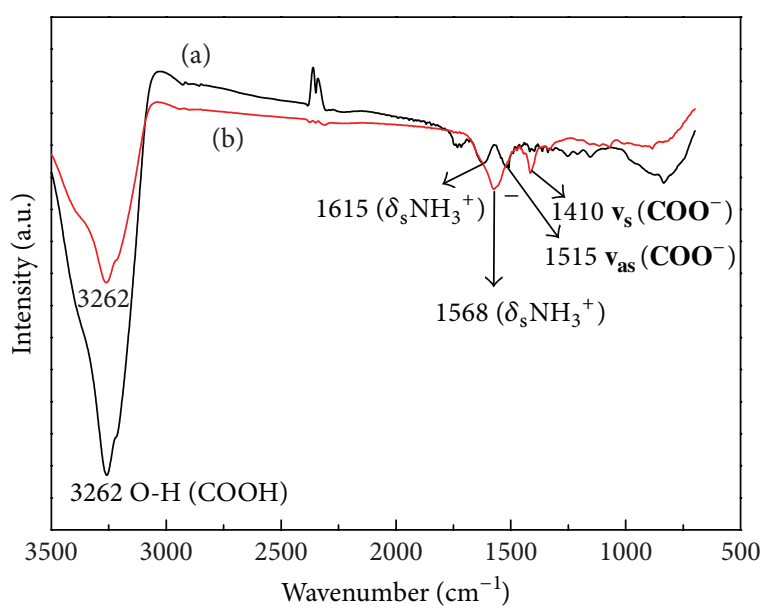

FIGURE 3: IR spectra of DABA (curve (a)) and DABA-Co(II) (curve (b)) $\left(C=1.0 \mathrm{~mol} \cdot \mathrm{dm}^{-3}\right)$.

weak absorption at $520 \mathrm{~nm}$ (Figure 1, curve (b)). However, when the ligand and cobalt salt were mixed $(\mathrm{v}: \mathrm{v}=1: 1)$ under $\mathrm{N}_{2}$ atmosphere and adjusted to basic conditions, the mixed solution exhibited yellow color and showed two main absorption peaks at $\lambda=314$ and $384 \mathrm{~nm}$. This finding clearly shows the formation of the complex (Figure 1, curve (c)). When $\mathrm{N}_{2}$ was replaced with $\mathrm{O}_{2}$, the absorption of the solution increased immediately (Figure 1, curve (d)), and the color of the complex solution rapidly changed from light yellow to dark yellow, which indicates that the complex of $\mathrm{Co}(\mathrm{DABA})_{2}$ is easily oxygenated.

According to the $A-\mathrm{pH}$ curve (Figure 2), complexation started from $\mathrm{pH} 7.8$ and completed at $\mathrm{pH} 10$, as the absorption of the solution reached a maximum in the $\mathrm{pH}$ region from 10 to 10.5 . Thus, $\mathrm{pH} 10$ was selected for the succeeding tests.

3.1.2. IR Spectroscopy. IR characterization of the DABA$\mathrm{Co}$ (II) complex is shown in Figure 3. DABA (Figure 3, curve (a)) presents a strong peak of hydroxyl association at $3262 \mathrm{~cm}^{-1}$, as well as two weak peaks of amino stretching 


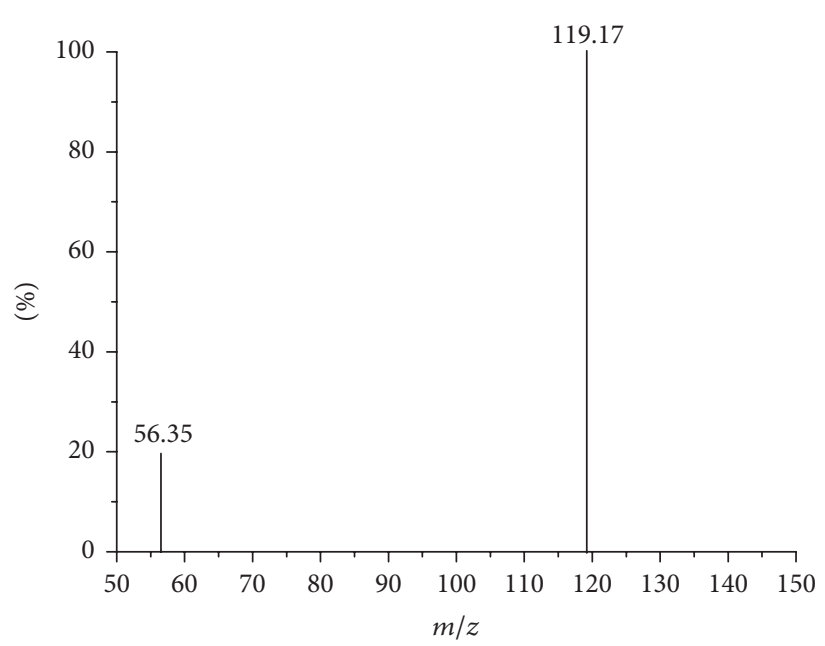

(a)

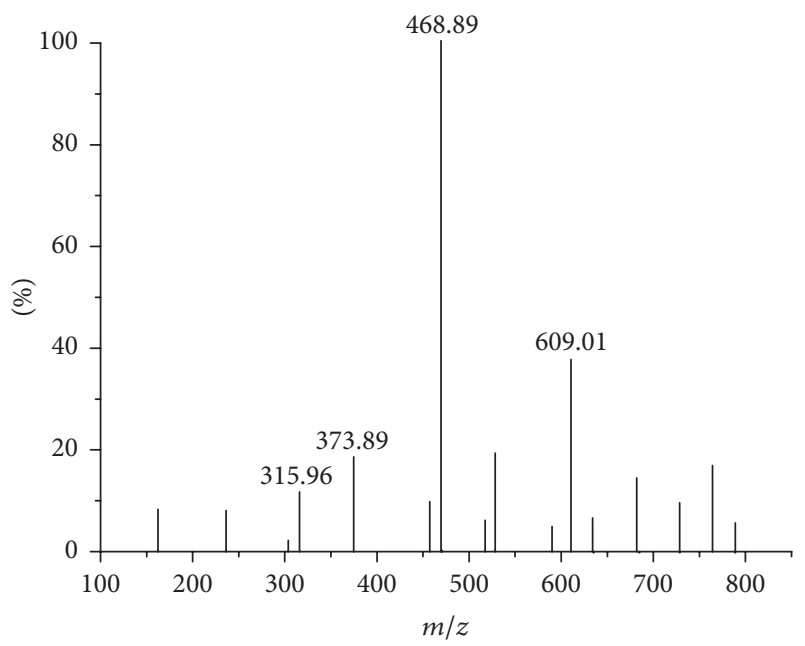

(b)

FIgURE 4: Full-scan positive electrospray mass spectrum of DABA (a) and DABA-Co(II) (b).

vibration and carboxyl asymmetric stretching vibration at 1615 and $1515 \mathrm{~cm}^{-1}$, respectively. In the DABA-Co(II) system (Figure 3, curve (b)), when DABA is coordinated with $\mathrm{Co}(\mathrm{II})$, the peak at $3262 \mathrm{~cm}^{-1}$ becomes weak, the peak at $1515 \mathrm{~cm}^{-1}$ disappears, and the peak at $1615 \mathrm{~cm}^{-1}$ shifts to red at $1568 \mathrm{~cm}^{-1}$. Therefore, the peak changes reveal that the amino group is involved in coordination and show that the ligand DABA and Co(II) form a complex in basic aqueous solution.

3.1.3. Mass Spectrometry. The ligand and the DABA-Co(II) complex were analyzed by MS, and the mass spectra are shown in Figure 4. The positive ion mass spectrum of DABA is shown in Figure 4(a). The $m / z 119.17$ fragment was the DABA base peak, which corresponds to the protonated molecule ion $[\mathrm{L}+\mathrm{H}]^{+}$. In Figure $4(\mathrm{~b})$, the main fragment peaks are $m / z 609.01,468.89,373.89$, and 315.96 . The peaks could be assigned accordingly to $\left[\mathrm{CoL}_{2}-\mathrm{O}_{2}-\mathrm{CoL}_{2}-\right.$ $\left.2 \mathrm{O}-2 \mathrm{H}^{+}+\mathrm{Na}^{+}\right]$or $\left[2\left(\mathrm{CoL}_{2}\right)-2 \mathrm{H}^{+}+\mathrm{Na}^{+}\right](m / z 609.01),\left[\mathrm{Co}_{2} \mathrm{~L}_{3}{ }^{-}\right.$ $3 \mathrm{H}]\left(\mathrm{m} / z\right.$ 468.89), [CoL $\left.{ }_{2}-2 \mathrm{H}^{+}+\mathrm{Ac}^{-}+\mathrm{Na}^{+}\right](m / z$ 373.89), and $\left[\mathrm{CoL}_{2}-2 \mathrm{H}^{+}+\mathrm{Na}^{+}\right](m / z$ 315.96). These fragments all confirm the formation of the complex and show that the composition of the complex is $\mathrm{CoL}_{2}$.

\subsection{Composition of the Complex}

3.2.1. Molar Ratio Method. The composition of the complex was determined by molar ratio method [29]. The results in Figure 5 show that the intersection of curves occurs at $2: 1$ of the ligand/Co, and the $\mathrm{L}$ : Co ratio is confirmed as $2: 1$. These results indicate that the composition of the complex is $\mathrm{CoL}_{2}$.

3.2.2. Gas Volumetric Method. The capacity of oxygen uptake and the ratio of complex to dioxygen can be determined by volumetry. $10.0 \mathrm{~mL}$ of $\mathrm{Co}$ (II) $\left(1.0 \times 10^{-1} \mathrm{~mol} \cdot \mathrm{dm}^{-3}\right)$ and $10.0 \mathrm{~mL}$ of DABA $\left(2.0 \times 10^{-1} \mathrm{~mol} \cdot \mathrm{dm}^{-3}\right)$ were mixed together in a conical flask in a glove box and determined by gas

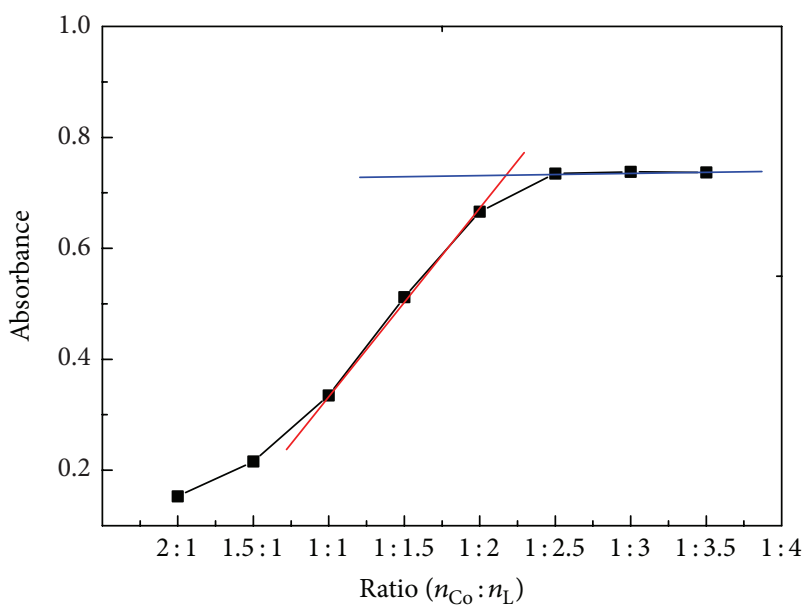

FIGURE 5: Proportions of the complexes determined by molar ratio method.

volumetric method [29]. The volumetry results presented in Figure 6 show that $0.5 \mathrm{mmol}$ of $\mathrm{Co}(\mathrm{DABA})_{2}$ in aqueous solution can absorb approximately $5.6 \mathrm{~mL}$ of oxygen within $5 \mathrm{~h}$. These results reveal that $1 \mathrm{~mol}$ of $\mathrm{Co}(\mathrm{DABA})_{2}$ can take up $0.5 \mathrm{~mol}$ of oxygen and that the composition of the oxygenated complex is $\left(\mathrm{CoL}_{2}\right)_{2} \mathrm{O}_{2}$. This finding is consistent with the $\mathrm{Co} / \mathrm{O}_{2}$ ratio in His-Co(II) oxygen complexes $[24,25]$.

Based on the abovementioned results, we can conclude that the complex forms immediately. In addition, the complex can be easily oxygenated when the two solutions of $\mathrm{Co}(\mathrm{II})$ and DABA are mixed and bubbled with dioxygen, and the composition of the oxygenated complex is $\left(\mathrm{CoL}_{2}\right)_{2} \mathrm{O}_{2}$. Therefore, in the following experiments, the concentration ratio of $\mathrm{Co}(\mathrm{II})$ and DABA was considered as $1: 2$, and the ratio of solution volumes was considered as $1: 1$. All tests were conducted rapidly after the two solutions of $\mathrm{Co}(\mathrm{II})$ and DABA were mixed and adjusted to $\mathrm{pH} 10$. 


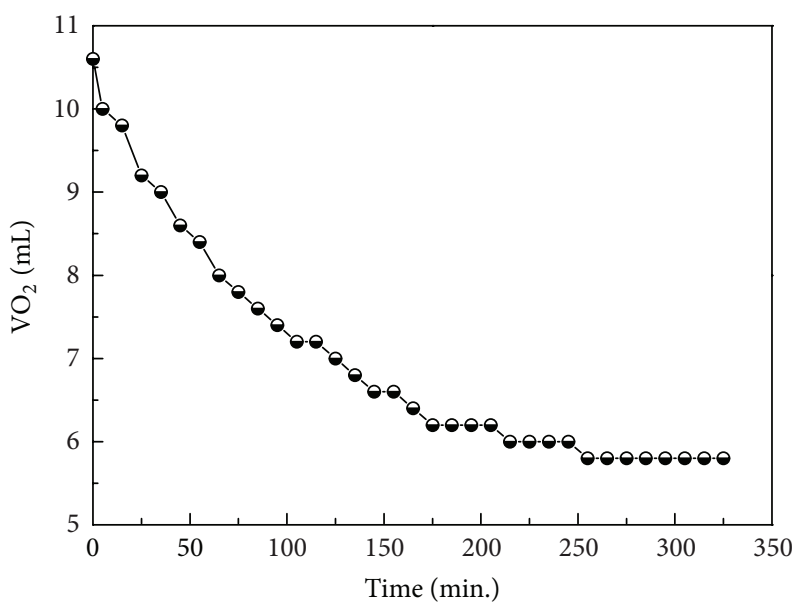

Figure 6: Absorbed volume of oxygen as determined by gas volumetric method.

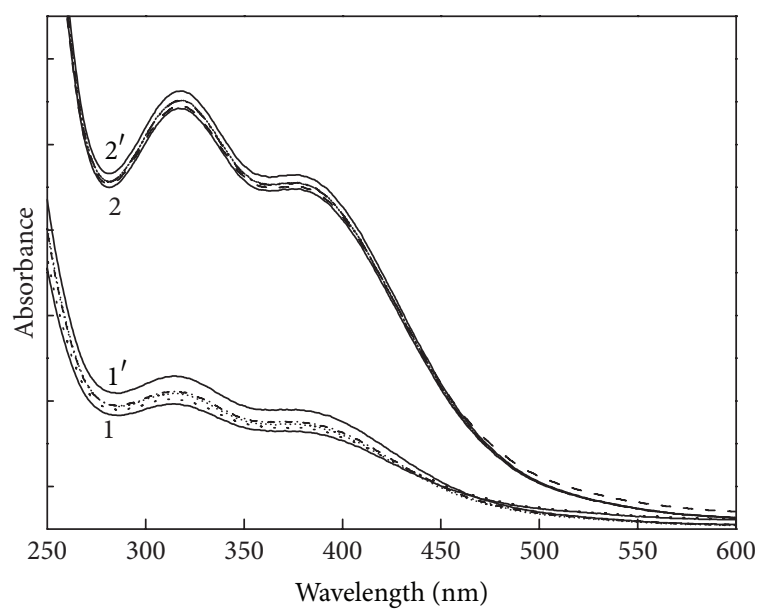

FIGURE 7: Optical absorption spectra of DABA-Co(II) in aqueous solution and at room temperature. Spectrum 1 was obtained with DABA-Co(II) solution saturated with $\mathrm{N}_{2}$. Spectrum 2 was obtained with DABA-Co(II) solution saturated with $\mathrm{O}_{2}$. Spectra $1^{\prime}$ and $2^{\prime}$ were obtained on the fifth cycle of alternate bubbling of $\mathrm{N}_{2}$ and $\mathrm{O}_{2}$ into the DABA-Co(II) solution $\left(C_{\mathrm{DABA}}=4.0 \times 10^{-4} \mathrm{~mol} \cdot \mathrm{dm}^{-3}\right.$ and $C_{\mathrm{Co}(\mathrm{II})}$ $=2.0 \times 10^{-4} \mathrm{~mol} \cdot \mathrm{dm}^{-3}$ ).

\subsection{Reversible Ability}

3.3.1. UV-Vis Spectrophotometry. The DABA-Co(II) complex is easily oxygenated in aqueous solution at room temperature, and similar oxygenation reaction quickly occurs in air. As shown in Figure 1, the spectra of the original complex and the oxygenated complex are evidently different. Therefore, the UV-Vis spectra can be used to determine oxygenation reversibility. When $\mathrm{N}_{2}$ and $\mathrm{O}_{2}$ were alternately fed into the DABA-Co(II) solution, the spectra of the solution changed accordingly (Figure 7). After five cycles of $\mathrm{N}_{2} / \mathrm{O}_{2}$ exchanging, both the spectra of the complex in $\mathrm{N}_{2}$ and in $\mathrm{O}_{2}$ changed slightly, showing that the oxygenation and deoxygenation reactions of the DABA-Co(II) complex are reversible and demonstrating excellent reversibility.

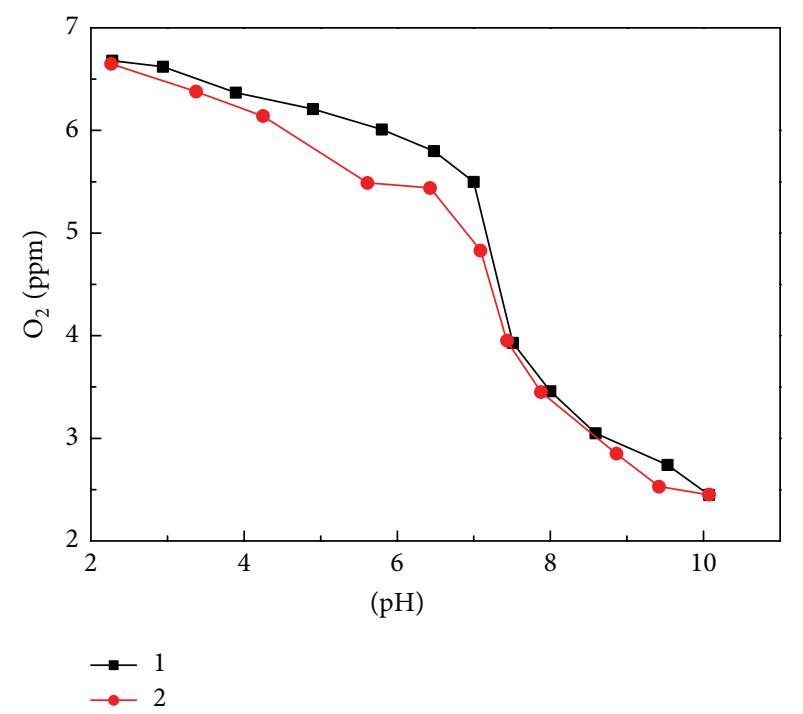

FIGURE 8: Evolution of dissolved oxygen concentration as a function of solution $\mathrm{pH}\left(C_{\mathrm{DABA}}=1.2 \times 10^{-3} \mathrm{~mol} \cdot \mathrm{dm}^{-3}, C_{\mathrm{Co}(\mathrm{II})}=6.0 \times\right.$ $\left.10^{-4} \mathrm{~mol} \cdot \mathrm{dm}^{-3}\right)$.

3.3.2. Oxygenmetry. Oxygenmetry was used to detect dioxygen concentration in the solution to follow the oxygenation evolution of the complex. As shown in curve 1 of Figure 8, dioxygen concentration dropped sharply after $\mathrm{pH} 7$ and reached a plateau near $\mathrm{pH} 10$ with the increase in $\mathrm{pH}$. This finding suggests that the complex started to be oxygenated at $\mathrm{pH} 7$ and that the reaction completed at $\mathrm{pH} 10$. The $\mathrm{pH}$ of this solution was then adjusted from 10 to 2 with dilute $\mathrm{HCl}$. It can be seen that curve 2 almost coincided with curve 1, indicating that the oxygenation of the complex is reversible.

3.3.3. Reversibility of Dioxygen Uptake and Release. To investigate the durability of the DABA-Co(II) complex according to $\mathrm{O}_{2}$ uptake, we conducted oxygenation-deoxygenation of DABA-Co(II) continuously by purging $\mathrm{O}_{2}$ and $\mathrm{N}_{2}$ alternately in aqueous solution at $25^{\circ} \mathrm{C} \pm 0.1^{\circ} \mathrm{C}$. Our results show that, by alternately changing $\mathrm{N}_{2}$ and $\mathrm{O}_{2}$, oxygenation-deoxygenation cycles could be conducted continuously for 3 days and sustained for 260 cycles (Figure 9). It can be observed that oxygen uptake of the complex occurs rapidly and is completed in $2 \mathrm{~min}$ (Figure 9(a) (curve 1)). However, the deoxygenation rate is relatively slow; it took $15 \mathrm{~min}$ to fully release the absorbed dioxygen.

The rate constant for oxygenation $\left(k_{a}\right)$ of $\mathrm{Co}(\mathrm{DABA})_{2}$ was calculated using optical absorption data averaged from numerous individual cycles (Figure 9(a)). Data analysis suggest that the oxygenation reaction is a first-order reaction, with $k_{a}=0.0139 \mathrm{~s}^{-1}$, whereas deoxygenation reaction is more complicated. For this complex, the experiment demonstrates that the mechanism for the oxygenation reaction is SN1 while the mechanism for deoxygenation reaction is SN2. In the oxygenation reaction, the $\mathrm{Co}$ ion in $\mathrm{Co}(\mathrm{DABA})_{2}$ turned from a high spin state into low spin states. Therefore, the ion can combine with oxygen at the axial coordinate space through a one-step reaction to generate oxygenated 


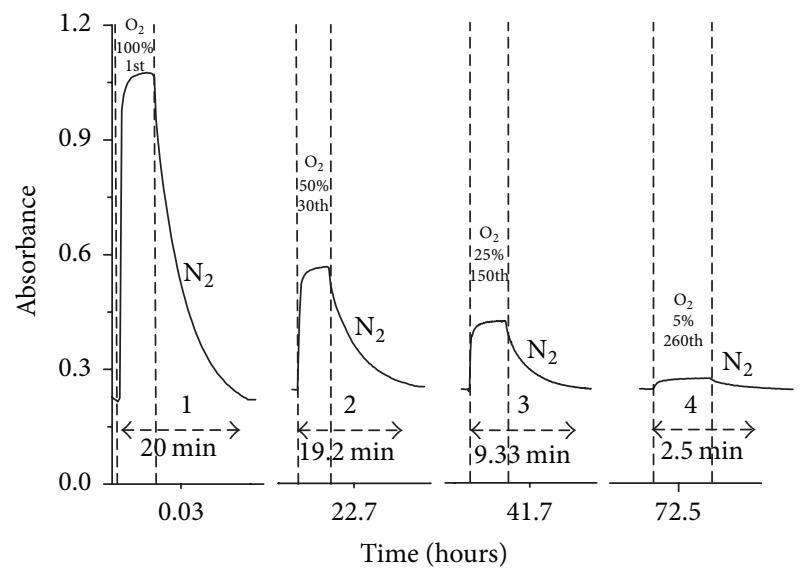

(a)

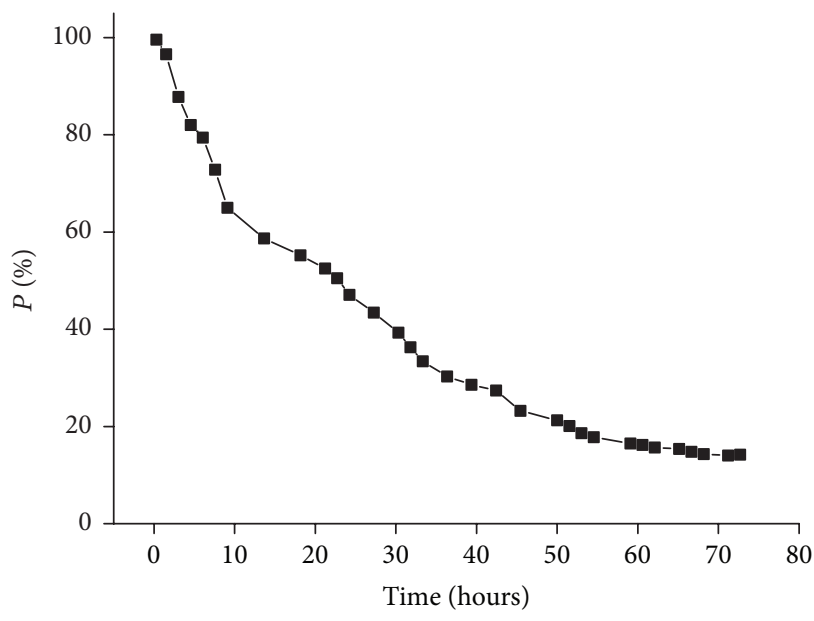

(b)

Figure 9: (a) Absorbance changed at $314 \mathrm{~nm}$ as $\mathrm{N}_{2}$ and $\mathrm{O}_{2}$ were bubbled alternately through an DABA-Co(II) complex aqueous solution $\left(C_{\mathrm{Co}(\mathrm{II})}=2.0 \times 10^{-4} \mathrm{~mol} \cdot \mathrm{dm}^{-3}\right)$. (b) Percentage of oxygenation capacity $(P \%)$ of DABA-Co(II) as a function of oxygenation time.

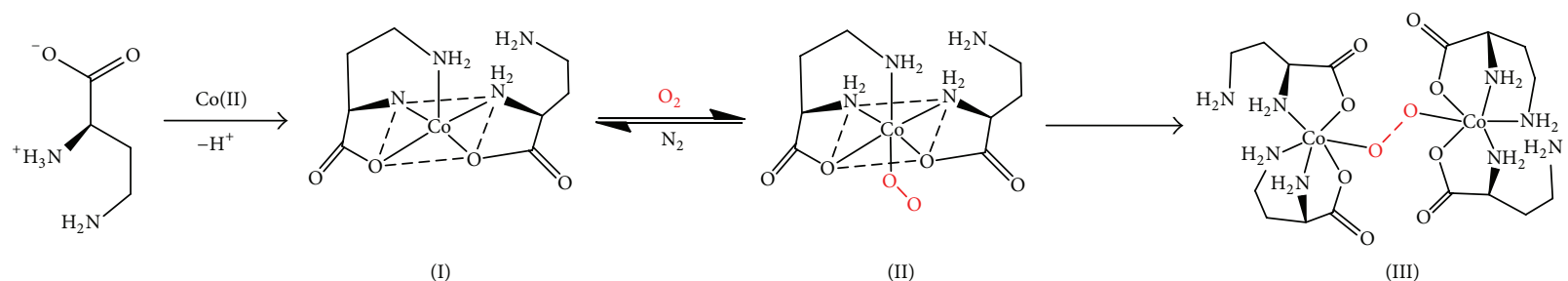

Scheme 1: Oxygenation mechanism for DABA-Co(II) complex with dioxygen.

complexes (Scheme 1). Meanwhile, the ion is converted into low spin states, in which the ligand-binding ability increases. Thus, the removal of oxygen becomes much more difficult, and a solvent (water) molecule was involved as a competitive ligand to crowd oxygen out to form a nonoxygenated complex, which results in a SN2 reaction. This result is similar to that of $\beta$-(2-Pyridyl)- $\alpha$-alanine [24].

3.3.4. Oxygenation Capacity. The reversibility of oxygenation and deoxygenation of Co (DABA $)_{2}$ was determined by monitoring the change in absorbance at $314 \mathrm{~nm}$ upon saturating the solution with $\mathrm{O}_{2}$ and $\mathrm{N}_{2}$, respectively. The absorbance difference $\Delta A$ was used to evaluate $\mathrm{O}_{2}$ uptake capacity, and the number of oxygenation-deoxygenation cycles was used to estimate the endurance of the complex against autooxidation. Take $\Delta A=A_{\mathrm{O}_{2}}-A_{\mathrm{N}_{2}}$ and first $\Delta A$ as $\Delta A_{0}: P \%=\Delta A / \Delta A_{0} *$ $100 \%$. The percentage of oxygenation capacity $(P \%)$ was used as a function of oxygenation-deoxygenation cycle to evaluate the endurance of the complexes against autooxidation.

Figure 9 presents the decline trend of the oxygenation capacity of DABA-Co(II). The figure shows that the DABACo(II) complex maintained $50 \%$ of its original oxygenation capacity after 30 cycles nearly in one day. Afterward, degradation slowed down, and 5\% of the original oxygenation capacity remained after more than 260 cycles and 3 days. This result proves the excellent oxygenation-deoxygenation durability of DABA-Co(II) complex $[14,15]$.
3.3.5. DFT Calculation. To clarify the oxygenation and deoxygenation of the DABA complexes, we carried out DFT calculations using the G03 quantum chemistry software [29]. The structural models of the studied compounds are shown in Figure 10. For the deoxygenated configuration of $\mathrm{Co}(\mathrm{DABA})_{2}$, we proposed two kinds of configuration, as shown in Figure 10. The first configuration is in a transconfiguration with a 4-amino in para-position (Figure 10(a)), and the second configuration is in a cis-configuration (Figure $10(\mathrm{~b})$ ). The calculation results show that the energy levels of cis-configuration are lower than those of the transconfiguration $\left(\Delta G=-228.95 \cdot \mathrm{kJ} \mathrm{mol}^{-1}\right)$. This finding indicates that the cis-configuration is the main species in the solution. The results are similar to those of bis[b-(2-pyridyl)-aalaninato]-Co(II), [PyA-Co(II)] [24, 30].

During the formation of the oxygenated complexes, the electron of $e_{g}$ orbitals of $\mathrm{Co}(\mathrm{II})$ would transfer to $\pi^{*}$ orbitals of dioxygen to form the $\mathrm{Co}-\mathrm{O}_{2}$ bond. For the cisconfiguration, the structure is almost unaltered, and only dioxygen occupies the originally unoccupied position. The dioxygen bond length increased from $0.1207 \mathrm{~nm}$ of the free state to $0.1359 \mathrm{~nm}$ in the coordinated state. These values are similar to the calculation values (from $0.1207 \mathrm{~nm}$ to $0.1357 \mathrm{~nm}$ ) of PyA-Co(II) [24], indicating that oxygenation and deoxygenation are similar to those of the PyA-Co(II) system. However, by comparing the dimer oxygenation species in both systems, we noticed that the bond length of $\mathrm{O}-\mathrm{O}$ was different. The dioxygen bond length is $0.1493 \mathrm{~nm}$ for 


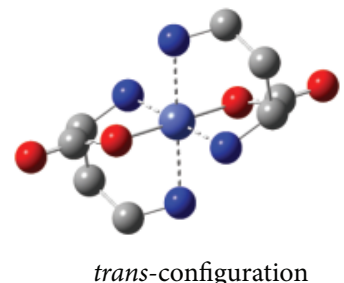

(a)

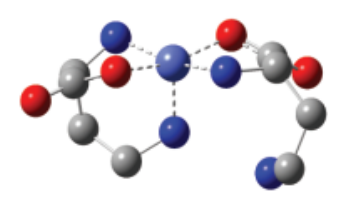

cis-configuration

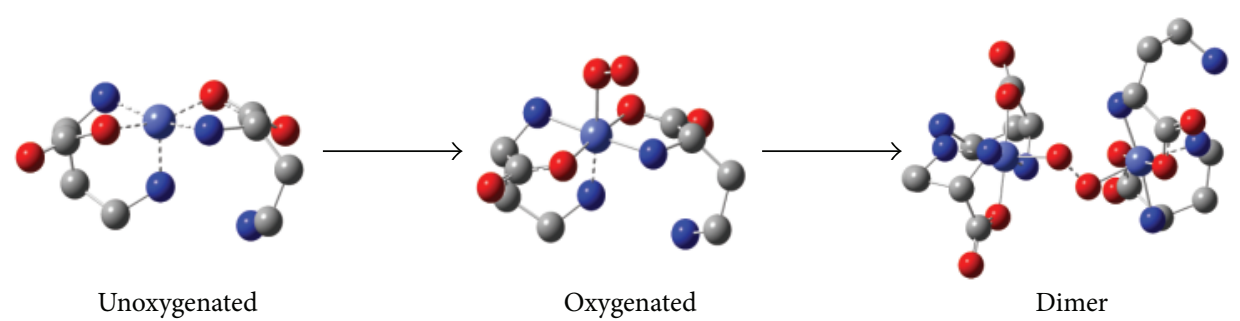

(c)

Figure 10: ((a), (b)) Two proposed deoxygenation configurations of $\mathrm{Co}(\mathrm{DABA})_{2}$ and (c) simulation of oxygenation of Co(DABA $)_{2}$.

DABA-Co(II) system and $0.1454 \mathrm{~nm}$ for PyA-Co(II) system. Hence, the complex is prone to forming dimer oxygenation species and easily producing an irreversible oxidation, and oxygenation reversibility decreased. Therefore, the oxygenation reversibility of $\operatorname{Co}(\mathrm{DABA})_{2}$ is slightly lower than that of the PyA-Co(II) system, despite the similar coordination structures of the two complexes.

Based on the simulated oxygenation configuration, we here propose model which supports 4-amino dissociates in one ligand for cis-configurations. This 4-dissociated amino group may form bridging coordination with another $\mathrm{Co}(\mathrm{DABA})_{2}$ complex, leading to the emergence of $\left[\mathrm{Co}_{2}(\mathrm{DABA})_{3}\right]$ and $\left[\mathrm{Co}(\mathrm{DABA})_{2}\right]_{2}$ species in $\mathrm{MS}$ determination.

\section{Conclusion}

The oxygenation behavior of the DABA-Co(II) complex in aqueous solution was investigated. The formation of the complex was confirmed by UV-Vis, IR, and MS characterization, and the composition of the complex was determined by gas volumetric method, molar ratio method, and MS. The results indicate that the proportion of oxygenated complex is $n(\mathrm{Co}): n(\mathrm{DABA}): n\left(\mathrm{O}_{2}\right)=1: 2: 0.5$. The reversibility of oxygenation and deoxygenation of the complex in aqueous solution was tested with oxygenmetry and UV-Vis, and both results confirm that the oxygenation process is a reversible reaction. Furthermore, the complex exhibit excellent oxygen uptake ability and can continuously absorb and release oxygen for 3 days by alternately changing $\mathrm{N}_{2}$ and $\mathrm{O}_{2}$, over 260 cycles. The excellent reversible oxygenation property of the complex further confirmed our assumption that a $\mathrm{Co}$ (II) complex with a histidine analogue ligand uptakes oxygen reversibly. The study on relationship between structural detail and oxygenation properties will help to explore new families of oxygen carriers.

\section{Competing Interests}

The authors declare that there is no conflict of interests regarding the publication of this paper.

\section{Acknowledgments}

Financial support from the National Natural Science Foundation of China (nos. 21162027, 21261022) is gratefully acknowledged.

\section{References}

[1] E. C. Niederhoffer, J. H. Timmons, and A. E. Martell, “Thermodynamics of oxygen binding in natural and synthetic dioxygen complexes," Chemical Reviews, vol. 84, no. 2, pp. 137-203, 1984.

[2] N. Kindermann, S. Dechert, S. Demeshko, and F. Meyer, "Proton-induced, reversible interconversion of a $\mu$-1,2-peroxo and a $\mu$-1,1-hydroperoxo dicopper(II) complex," Journal of the American Chemical Society, vol. 137, no. 25, pp. 8002-8005, 2015.

[3] J. Cho, S. Jeon, E. I. Solomon et al., "Structure and reactivity of a mononuclear non-haem iron(III)-peroxo complex," Nature, vol. 478, no. 7370, pp. 502-505, 2011.

[4] L. J. Murray, M. Dinca, J. Yano et al., "Highly-selective and reversible $\mathrm{O}_{2}$ binding in $\mathrm{Cr}_{3}\left(1,3,5\right.$-benzenetricarboxylate), ${ }_{2}$, Journal of the American Chemical Society, vol. 132, no. 23, pp. 7856-7857, 2010.

[5] W. Gao, B. Sha, W. Zou et al., "Cationic amylose-encapsulated bovine hemoglobin as a nanosized oxygen carrier," Biomaterials, vol. 32, no. 35, pp. 9425-9433, 2011.

[6] E. J. Milner-White and M. J. Russell, "Functional capabilities of the earliest peptides and the emergence of life," Genes, vol. 2, no. 4, pp. 671-688, 2011.

[7] W. Nam, "Synthetic mononuclear nonheme iron-oxygen intermediates," Accounts of Chemical Research, vol. 48, no. 8, pp. 2415-2423, 2015. 
[8] J. P. Klinman, "How do enzymes activate oxygen without inactivating themselves?" Accounts of Chemical Research, vol. 40, no. 5, pp. 325-333, 2007.

[9] S. Kim, J. Y. Lee, R. E. Cowley et al., "A $\mathrm{N}_{3} \mathrm{~S}_{\text {(thioether) }}$-ligated Cu $\mathrm{Cu}^{I I}$ superoxo with enhanced reactivity," Journal of the American Chemical Society, vol. 137, no. 8, pp. 2796-2799, 2015.

[10] W. Nam, Y. M. Lee, and S. Fukuzumi, "Tuning reactivity and mechanism in oxidation reactions by mononuclear nonheme iron(IV)-oxo complexes," Accounts of Chemical Research, vol. 47, no. 4, pp. 1146-1154, 2014.

[11] J. Cho, H. Y. Kang, L. V. Liu, R. Sarangi, E. I. Solomon, and W. Nam, "Mononuclear nickel(ii)-superoxo and nickel(iii)-peroxo complexes bearing a common macrocyclic TMC ligand," Chemical Science, vol. 4, no. 4, pp. 1502-1508, 2013.

[12] S. V. Kryatov, E. V. Rybak-Akimova, and S. Schindler, "Kinetics and mechanisms of formation and reactivity of non-heme iron oxygen intermediates," Chemical Reviews, vol. 105, no. 6, pp. 2175-2226, 2005.

[13] N. Kitajima and Y. Moro-oka, "Copper-dioxygen complexes. Inorganic and bioinorganic perspectives," Chemical Reviews, vol. 94, no. 3, pp. 737-757, 1994.

[14] H. M. Wen, X. Zhang, H. Li, F. Yue, and J. D. Wang, "Contrast study of the oxygenation of Co(II) complexes with different bi/poly-dentate ligands," Chemical Journal of Chinese Universities, vol. 34, no. 10, pp. 2262-2269, 2013.

[15] X. C. Zhang, F. Yue, Y. Huang et al., "Comparative study for oxygenation properties of cobalt complexes with histidine, histidinol and histamine," Chinese Journal of Inorganic Chemistry, vol. 29, p. 2387, 2013.

[16] L. L. Liu, H. X. Li, L. M. Wan, Z. G. Ren, H. F. Wang, and J. P. Lang, "A $\mathrm{Mn}(\mathrm{III})$-superoxo complex of a zwitterionic calix[4] arene with an unprecedented linear end-on Mn(III)$\mathrm{O}_{2}$ arrangement and good catalytic performance for alkene epoxidation," Chemical Communications, vol. 47, no. 39, pp. 11146-11148, 2011.

[17] M. R. Tine, "Cobalt complexes in aqueous solutions as dioxygen carriers," Coordination Chemistry Reviews, vol. 256, no. 1-2, pp. 316-327, 2012.

[18] E. Vinck, E. Carte, D. M. Murphy, and S. V. Doorslaer, "Observation of an organic acid mediated spin state transition in a Co(II)-Schiff base complex: an EPR, HYSCORE, and DFT study," Inorganic Chemistry, vol. 51, no. 15, pp. 8014-8024, 2012.

[19] J. P. Collman and L. Fu, "Synthetic models for hemoglobin and myoglobin," Accounts of Chemical Research, vol. 32, no. 6, pp. 455-463, 1999.

[20] C. Johnson, B. Long, J. G. Nguyen et al., "Correlation between active center structure and enhanced dioxygen binding in $\mathrm{Co}$ (salen) nanoparticles: characterization by in situ infrared, Raman, and X-ray absorption spectroscopies," Journal of Physical Chemistry C, vol. 112, no. 32, pp. 12272-12281, 2008.

[21] C. Johnson, S. Ottiger, R. Pini et al., "Near-Stoichiometric $\mathrm{O}_{2}$ binding on metal centers in Co(salen) nanoparticles," AIChE Journal, vol. 55, no. 4, pp. 1040-1045, 2009.

[22] J. Cho, J. Woo, and W. Nam, "A chromium(III)-superoxo complex in oxygen atom transfer reactions as a chemical model of cysteine dioxygenase," Journal of the American Chemical Society, vol. 134, no. 27, pp. 11112-11115, 2012.

[23] P. Comba, C. Haaf, S. Helmle, K. D. Karlin, S. Pandian, and A. Waleska, "Dioxygen reactivity of new bispidine-copper complexes," Inorganic Chemistry, vol. 51, no. 5, pp. 2841-2851, 2012.
[24] F. Yue, N. Song, Y. Huang et al., "Reversible oxygenation of bis[ $\beta$-(2-pyridyl)- $\alpha$-alaninato]Co(II) complex in aqueous solution at room temperature," Inorganica Chimica Acta, vol. 398, pp. 141-146, 2013.

[25] A. E. Martell, "Formation and stabilities of cobalt dioxygen complexes in aqueous solution," Accounts of Chemical Research, vol. 15 , no. 5 , pp. $155-162,1982$.

[26] J. D. Wang, E. Collange, D. J. Aymes, M. R. Paris, and R. Fournaise, "Propriétés physico-chimiques des iodohistidines. II. Etude protométrique, oxymétrique et spectrophotométrique de l'oxygénation de leurs complexes du Co (II)," Bulletin de la Société Chimique de France, vol. 131, pp. 30-36, 1994.

[27] X. C. Zhang, F. Yue, Y. Huang, P. Fu, X. Cheng, and J. D. Wang, "Reversible oxygenation properties of 2,3-diaminopropanoic acid cobalt complex," Chemical Journal of Chinese Universities, vol. 33, no. 7, pp. 1370-1375, 2012.

[28] M. J. Frisch, G. W. Trucks, H. B. Schlegel et al., GAUSSIAN 03, Revision E.01, Gaussian, Wallingford, Conn, USA, 2004.

[29] F. R. Xiao, L. Chen, J. D. Wang, R. L. Wu, F. Yue, and J. Li, "Studies on solid state synthesis and oxygenation property of cobalt(II) schiff base (vanilline polyamine) complexes," Acta Chimica Sinica, vol. 64, no. 15, pp. 1517-1522, 2006.

[30] S. R. Ebner and R. J. Angelici, "Preparation and characterization of the copper(II) and zinc(II) complexes of D-.beta.(2-pyridyl)-.alpha.-alaninate and their condensation products with acetone," Inorganic Chemistry, vol. 20, no. 9, pp. 2971-2977, 1981. 

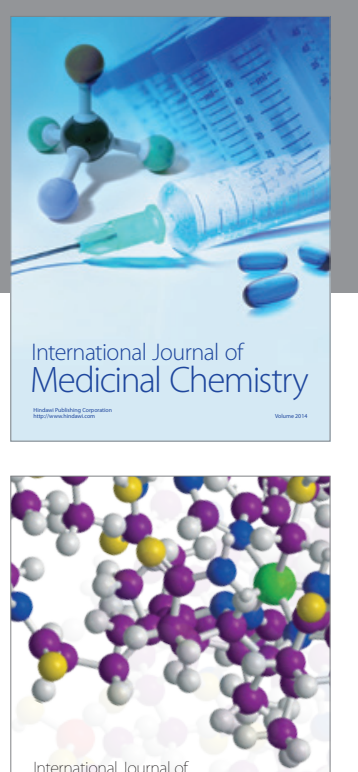

Carbohydrate Chemistry

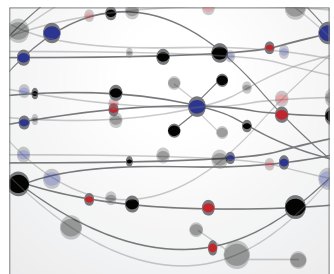

The Scientific World Journal
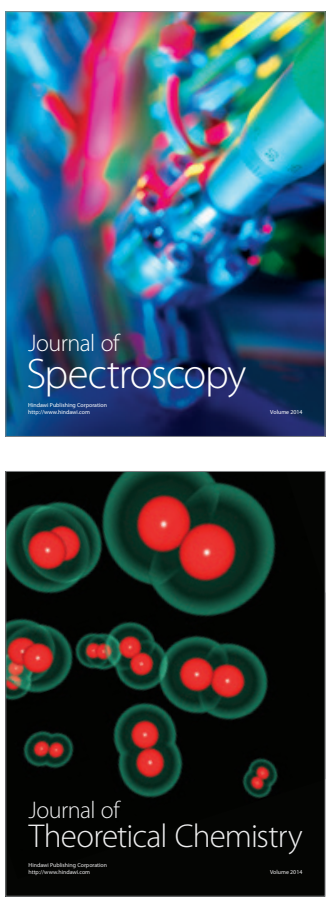
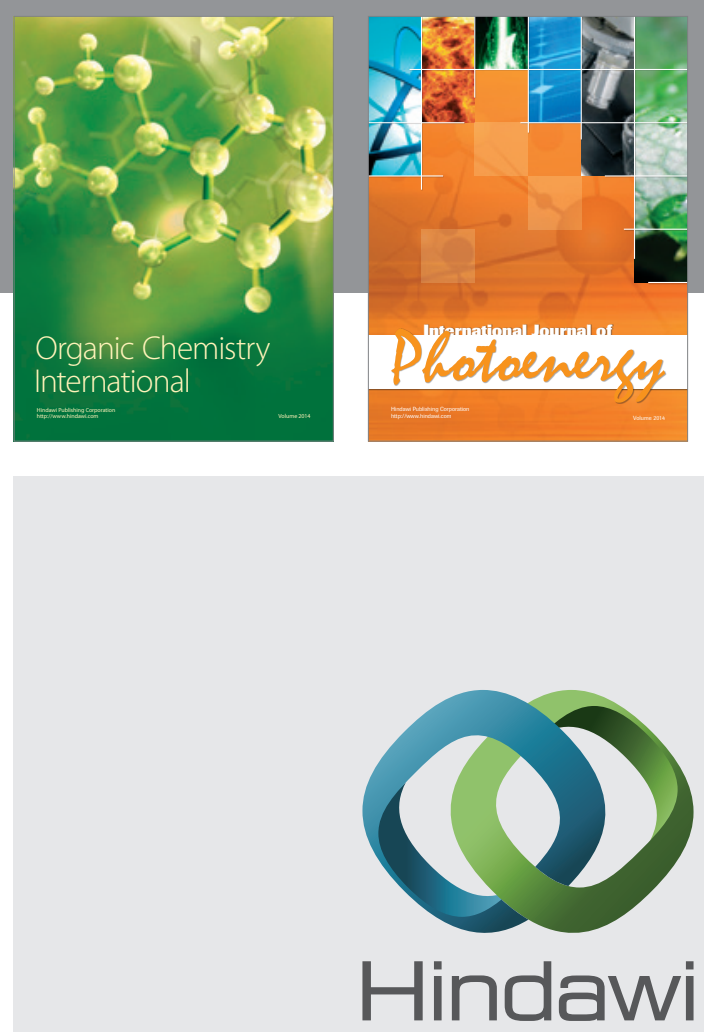

Submit your manuscripts at

http://www.hindawi.com

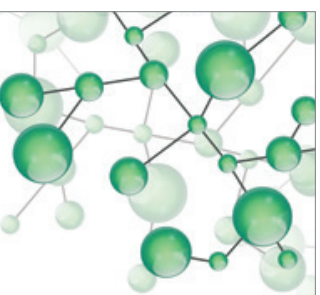

International Journal of

Inorganic Chemistry

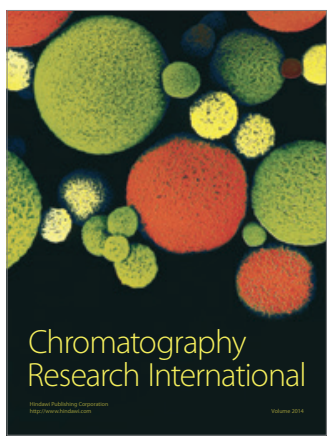

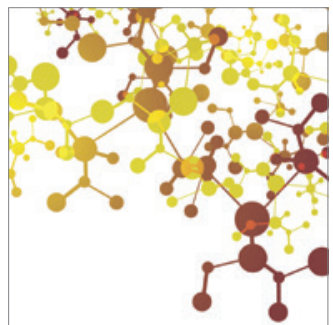

Applied Chemistry
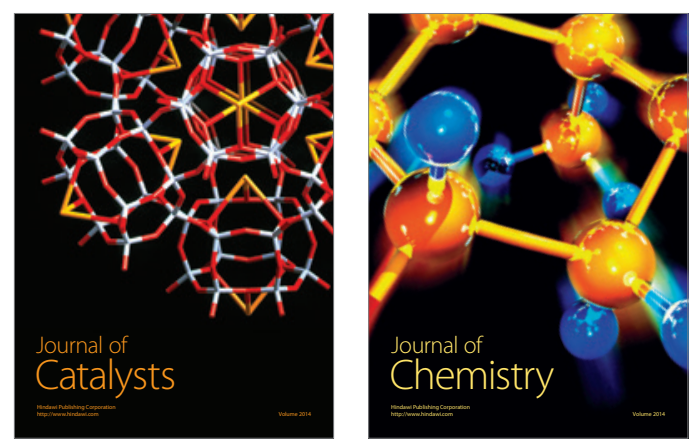
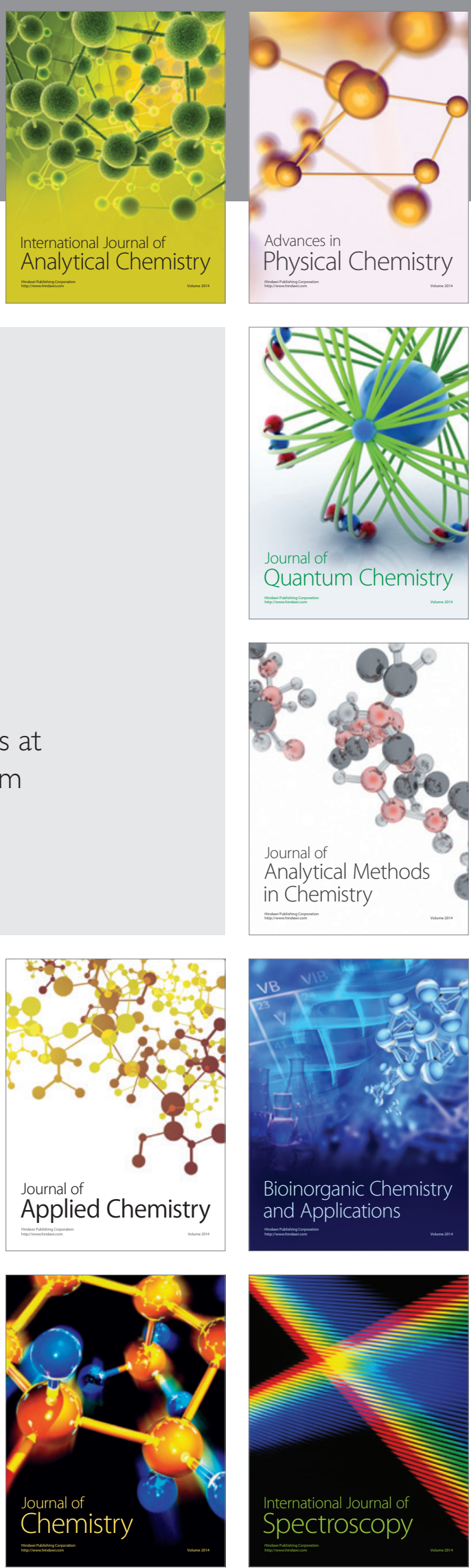